\title{
Successful allograft root re-replacement for prosthetic valve endocarditis with improvement of renal function in a Jehovah's Witness patient
}

\author{
Syed T. Hussain, MD, ${ }^{a}$ Eugene H. Blackstone, $\mathrm{MD},{ }^{\mathrm{a}, \mathrm{b}}$ and Gösta B. Pettersson, $\mathrm{MD}, \mathrm{PhD},{ }^{\mathrm{a}}$ Cleveland, Ohio
}

Video clip is available online.

Cardiac surgery in Jehovah's Witness patients (Witnesses) who refuse the use of blood products is now increasingly performed in both elective and urgent situations with excellent outcomes. ${ }^{1-5}$ Various case reports and larger series continue to report successful cardiac surgical operations in more complex scenarios, including acute type A dissections, root repairs, and various reoperative surgeries. Although the large majority of procedures in Witnesses remain standard primary operations, there have also been reports of more complex operations and reoperations. We report a successful allograft aortic root re-replacement in a Witness with prosthetic aortic valve infective endocarditis and renal failure.

\section{CLINICAL SUMMARY}

A 43-year-old male Witness who had undergone a porcine aortic root replacement 8 years previously was seen with constitutional symptoms and fever that had persisted for 2 to 3 months. An echocardiogram showed large vegetations on the aortic valve, but results of multiple blood cultures were negative. The patient's condition did not improve with antibiotic treatment, and the follow-up echocardiogram showed even larger vegetations. Repeat echocardiography (Video 1) at our institution showed large vegetations on the thickened aortic valve but no valve regurgitation, an unusual finding for the more common endocarditis pathogens. The patient's left ventricular ejection fraction was $30 \%$. Although blood culture results remained negative even without antibiotics, serologic study was positive for Histoplasma capsulatum, and a regimen of

\footnotetext{
From the Departments of Thoracic and Cardiovascular Surgery, ${ }^{\mathrm{a}}$ Heart and Vascular Institute, and Quantitative Health Sciences, ${ }^{\mathrm{b}}$ Research Institute, Cleveland Clinic, Cleveland, Ohio.

Disclosures: Authors have nothing to disclose with regard to commercial support.

Received for publication April 16, 2014; revisions received May 28, 2014; accepted for publication June 5, 2014; available ahead of print Aug 21, 2014.

Address for reprints: Gösta B. Pettersson, MD, PhD, Department of Thoracic and Cardiovascular Surgery, Cleveland Clinic, 9500 Euclid Ave, Desk J4-1, Cleveland, OH 44195 (E-mail: petterg@ ccf.org).

J Thorac Cardiovasc Surg 2014;148:e199-200

$0022-5223 / \$ 36.00$

Copyright (C) 2014 by The American Association for Thoracic Surgery

http://dx.doi.org/10.1016/j.jtcvs.2014.06.066
}

amphotericin B was started. The presenting hematocrit was $29 \%$, and the platelet count was $43,000 / \mu \mathrm{L}$. Although the patient's condition was considered inoperable, he was started on an intravenous iron supplement (twice weekly) and erythropoietin (initially 3 times per week). Because of worsening renal function, amphotericin B was stopped and replaced with itraconazole. Treatment with romiplostim for platelets and erythropoietin (40,000 units daily) increased his hematocrit to $38 \%$ and his platelets to $67,000 / \mu \mathrm{L}$. The patient's renal function had continued to deteriorate to a creatinine level of $4.5 \mathrm{mg} / \mathrm{dL}$, suggesting postinfectious glomerulonephritis as the most likely cause and indicating an imminent need for dialysis.

At this point, the patient underwent reoperative aortic root replacement with an allograft. Normothermic cardiopulmonary bypass with retrograde autologous blood priming to minimize the circuit prime volume, cell salvage, and aminocaproic acid were used. Operative findings included huge vegetations on the excised valve leaflet but no extra-aortic invasion. Cardiopulmonary bypass and aortic clamp times were 127 and 110 minutes, respectively. Postoperative bleeding was minimal, and hematocrit the day after surgery was $37 \%$. The patient received no blood products. His postoperative course was remarkable for immediate and rapid improvement in renal function, despite resumed treatment with amphotericin B. The patient was discharged on postoperative day 5 and was doing well with normal creatinine 3 months later.

\section{DISCUSSION}

Witnesses are undergoing increasingly complex cardiac surgical procedures with good outcomes as a result of bloodless strategies involving meticulous surgical, preoperative, and postoperative management. ${ }^{1-3}$ Preoperative management with iron supplementation and erythropoietin is used to elevate the hematocrit to $40 \%$ or more. Intraoperatively, fastidious hemostatic techniques are used to avoid bleeding. This is accomplished by careful evaluation of preoperative imaging studies for surgical planning, staying in the right surgical planes, maintaining hemostasis throughout the procedure, perfectly sizing the allograft or adjusting the annulus to the allograft if the available allograft is too small (internal diameter of allograft $2 \mathrm{~mm}$ smaller than the annulus), and focusing on perfect and meticulous suturing rather than cardiopulmonary bypass and 
aortic clamp times. We ensure that the allograft sits deep inside the annulus, performing a tension-free allograft to distal aorta anastomosis and wedging the larger end rather than trying to make up for size mismatch, and pack the surgical field for 30 minutes (without use of suction) after starting protamine.

Well-described techniques to minimize blood loss in such cases may include use of bone wax, judicious use of electrocautery and bipolar sealer (Aquamantys; Medtronic, Inc, Minneapolis, Minn), limited use of laparotomy pads and discard suction, acute normovolemic hemodilution, rapid autologous priming, small-volume oxygenators with small-diameter tubing and cell salvage, minimal laboratory testing, and intraoperative ultrafiltration. ${ }^{1-5}$

Bhaskar and colleagues ${ }^{1}$ reported results for 49 Witnesses undergoing cardiac surgery. They had significantly less bleeding, almost half that of non-Witness patients. Jassar and colleagues $^{2}$ reported excellent results in 91 Witnesses undergoing cardiac surgery, both elective and urgent, with their bloodless medicine program. Vaislic and colleagues ${ }^{3}$ reported their results for cardiac surgery in 500 consecutive Witnesses, 250 from 1991 to 2003 and 250 from 2003 to 2012. Thirty-day mortalities in the 2 groups were $3 \%$ and $1 \%$, respectively. All these large series demonstrate that progressive advances in perioperative management, improved perfusion techniques, meticulous surgical planning, and a "bloodless team approach" ${ }^{2}$ can allow well-selected Witnesses to undergo even complex cardiac surgery with remarkable safety. These results are possible to obtain with low risk of bleeding.

Our patient underwent reoperation for prosthetic aortic valve infective endocarditis complicated by anemia, thrombocytopenia, and renal failure. The agony that goes into the decision to operate or not for higher risk patients involves the patient, families, and the treating physicians. In the end, if we think we can possibly be successful, we will do it. The patient was extremely lucky that we were able to avoid bleeding completely, probably an important factor in his rapid postoperative reversal of renal function decline. The case illustrates that even a complex, reoperative allograft root replacement procedure can be performed safely in Witnesses. Our case interestingly also demonstrates the potential reversibility of infective endocarditis-induced renal injury.

\section{References}

1. Bhaskar B, Jack RK, Mullany D, Fraser J. Comparison of outcome in Jehovah's Witness patients in cardiac surgery: an Australian experience. Heart Lung Circ. 2010; $19: 655-9$

2. Jassar AS, Ford PA, Haber HL, Isidro A, Swain JD, Bavaria JE, et al. Cardiac surgery in Jehovah's Witness patients: ten-year experience. Ann Thorac Surg. 2012;93:19-25.

3. Vaislic CD, Dalibon N, Ponzio O, Ba M, Jugan E, Lagneau F, et al. Outcomes in cardiac surgery in 500 consecutive Jehovah's Witness patients: 21 year experience. J Cardiothorac Surg. 2012;7:95

4. Coselli JS, Buket S, Van Cleve GD. Successful reoperation for ascending aorta and arch aneurysm in a Jehovah's Witness. Ann Thorac Surg. 1994;58:871-3.

5. Holt RL, Martin TD, Hess PJ, Beaver TM, Klodell CT. Jehovah's Witnesses requiring complex urgent cardiothoracic surgery. Ann Thorac Surg. 2004;78:695-7.

\title{
Long-term outcome of off-pump palliation for hypoplastic left ventricle with glutaraldehyde fixation of the ductus arteriosus
}

\author{
Ryan J. Williams, BS, ${ }^{a}$ Daniel S. Levi, MD, ${ }^{a}$ Jamil Aboulhosn, MD, ${ }^{b}$ and Hillel Laks, MD, ${ }^{c}$ Los Angeles, \\ Calif
}

A newborn with a hypoplastic left heart was palliated with a novel surgical approach including glutaraldehyde fixation of the ductus arteriosus, aortopulmonary shunt placement, and pulmonary artery (PA) reconstruction without cardiopulmonary bypass. The long-term followup is reported.

From the Divisions of Pediatric Cardiology, ${ }^{\mathrm{a}}$ Cardiology, ${ }^{\mathrm{b}}$ and Cardiothoracic Surgery, ${ }^{\mathrm{c}}$ David Geffen School of Medicine at UCLA, Los Angeles, Calif.

Disclosures: Jamil Aboulhosn reports shares in On-X Valve company. All other authors have nothing to disclose with regard to commercial support.

Received for publication March 6, 2012; revisions received May 23, 2014; accepted for publication June 2, 2014.

Address for reprints: Daniel S. Levi, MD, 10833 Le Conte Ave, B2-427 MDCC, Los Angeles, CA 90095 (E-mail: DLevi@mednet.ucla.edu).

J Thorac Cardiovasc Surg 2014;148:e200-2

$0022-5223 / \$ 36.00$

Copyright (c) 2014 by The American Association for Thoracic Surgery

http://dx.doi.org/10.1016/j.jtcvs.2014.06.071

\section{CLINICAL SUMMARY}

A term neonate was born with heterotaxy, dextrocardia, unbalanced atrioventricular canal with regurgitation, double-outlet right ventricle, hypoplastic left ventricle, and aortic atresia with a 3-mm ascending aorta. There were bilateral superior venae cavae and an interrupted inferior vena cava with azygos continuation to the leftsided superior vena cava.

Stage I palliation was performed 7 days after birth (Figure 1). A 4-mm modified right Blalock-Taussig shunt was placed without cardiopulmonary bypass to the right PA. The proximal right PA was divided between clamps at its origin from the main PA and the stump was oversewn, leaving flow to the right PA from the shunt and antegrade flow to the left PA. The proximal left PA was then similarly clamped, divided, and oversewn leaving flow only to the 